\title{
REPENSANDO O PROJETO DE ILUMINAÇÃO: AVALIAÇÃO DE MÉTRICAS DE LUZ CIRCADIANA
}

\author{
CHAVES, Nathali Pimentel
}

Universidade Federal do Rio Grande do Sul (UFRGS), Programa de Pesquisa e Pósgraduação em Arquitetura (PROPAR), e-mail: nathali.chaves@ufrgs.br

MARTAU, Betina Tschiedel

Universidade Federal do Rio Grande do Sul (UFRGS), Programa de Pesquisa e Pósgraduação em Arquitetura (PROPAR), e-mail: betina.martau@ufrgs.br

\begin{abstract}
RESUMO
Nos últimos quinze anos, a pesquisa sobre os mecanismos que regem as relações entre a iluminação arquitetônica e os processos de regulação circadiana no corpo humano cresceram em produção. Porém, pouco se avançou na aplicação desses conceitos na prática de projeto. Os exemplos são poucos e a mensuração dos resultados dos mesmos não é clara. O problema está relacionado a descoberta, nos anos 2000, do fotorreceptor no olho humano (ipRGC) e da sua relação direta com o ciclo claro-escuro, não apenas no processo da visão, mas também na regulação de processos fisiológicos (ritmos circadianos). Os métodos de projeto existentes são voltados ao conforto visual e não atendem as necessidades relacionadas a regulação circadiana. Esse artigo busca comparar a aplicação de duas métricas circadianas com os requisitos para desempenho de tarefas visuais em um espaço arquitetônico. As métricas avaliadas foram o Lux Melanópico Equivalente e Estímulo Circadiano. A metodologia abrangeu estudo de caso (escritório hipotético) através de simulação computacional (DIALuxEvo 8). Foram utilizados dois planos de cálculo de iluminância com malha padrão: no plano de trabalho (iluminância horizontal), seguindo a ABNT NBR ISO/CIE 8995-1; e ao nível do observador (1,20m) com cálculo de iluminância vertical segundo recomendações das métricas circadianas. Identificamos diferenças entre as funções de sensibilidade espectral, métodos de conversão e que os requisitos para visão não atenderiam aos requisitos para saúde. $O$ estudo buscou evidenciar o impacto que as métricas circadianas causam no processo de projeto de iluminação e normas vigentes, contribuindo para discussão sobre a qualidade da iluminação.
\end{abstract}

Palavras-chave: Projeto luminotécnico, lluminação circadiana, Simulação computacional, Métricas circadianas.

\begin{abstract}
During the last fifteen years, the research about mechanisms that set the relations between architectural lighting and circadian regulation processes in the human body grew in production. However, little progress has been made in applying these concepts to architectural design practice. There are just few examples and theirs impacts evaluation are not clear. The problem is related with the discovery, in the 2000's, of the photoreceptor in the human eye (ipRGC) and its direct relation with the light-dark cycle, not only with the vision processes, but also in the physiological processes (circadian rhythms). The available design methods are focused on visual comfort and do not meet needs related with circadian regulation. This article pursues to compare two circadian lighting metrics with visual tasks performance requirements for an architectural space. Equivalent Melanopic Lux and Circadian Stimulus were the circadian lighting metrics evaluated. The methodology covered case study (hypothetical office) through computer simulation (DIALUXEVO8). Two calculation illuminance plans with a standard grid were used: a work plan (horizontal illuminance), according ABNT NBR ISO/CIE 8995-1; and at the observer's plan $(1,20 \mathrm{~m})$ with vertical illuminance calculation according circadian lighting recommendations. Differences were identified between the spectral sensibilities' functions and conversion methods. We also concluded, as expected, that the visual requirements do not meet
\end{abstract}

CHAVES, N. P.; MARTAU, B. T. Repensando o projeto de iluminação: avaliação de métricas de luz circadiana. In: SIMPÓSIO BRASILEIRO DE QUALIDADE DO PROJETO NO AMBIENTE CONSTRUÍDO, 6., 2019, Uberlândia. Anais... Uberlândia: PPGAU/FAUED/UFU, 2019. p. 532-543. DOI https://doi.org/10.14393/sbqp19050. 
health requirements considering the design methods. The purpose of the study was to highlight the circadian lighting metrics impact in the lighting design process and current standards, contributing with the discussion about lighting quality.

Keywords: Lighting design, Circadian lighting, Computer simulation, Circadian metrics.

\section{INTRODUÇÃO}

Por muito tempo, a base dos projetos luminotécnicos era garantir as condições de conforto visual com iluminância adequada e evitando ofuscamentos. Ferramentas de cálculo e simulação tornaram-se fundamentais para acelerar o processo de projeto e alcançar representações mais realísticas dos efeitos da luz. Porém, a introdução da tecnologia Light Emitting Diodes (LED) e a descoberta de novos processos fisiológicos medidos pela luz, geraram o que poderíamos chamar de uma "revolução Iuminotécnica". O LED, por implementar equipamentos com desempenho luminoso mais eficiente, porém com comportamento fotométrico diferente das antigas incandescentes $e$ fluorescentes e o segundo, por exigir conhecimentos multidisciplinares para lidar com os impactos da iluminação na saúde dos usuários, principalmente em relação a regulação dos ritmos circadianos, cuja alteração está diretamente relacionada a doenças como transtornos do humor, diabetes e câncer (TOUITOU; REINBERG; TOUITOU, 2017).

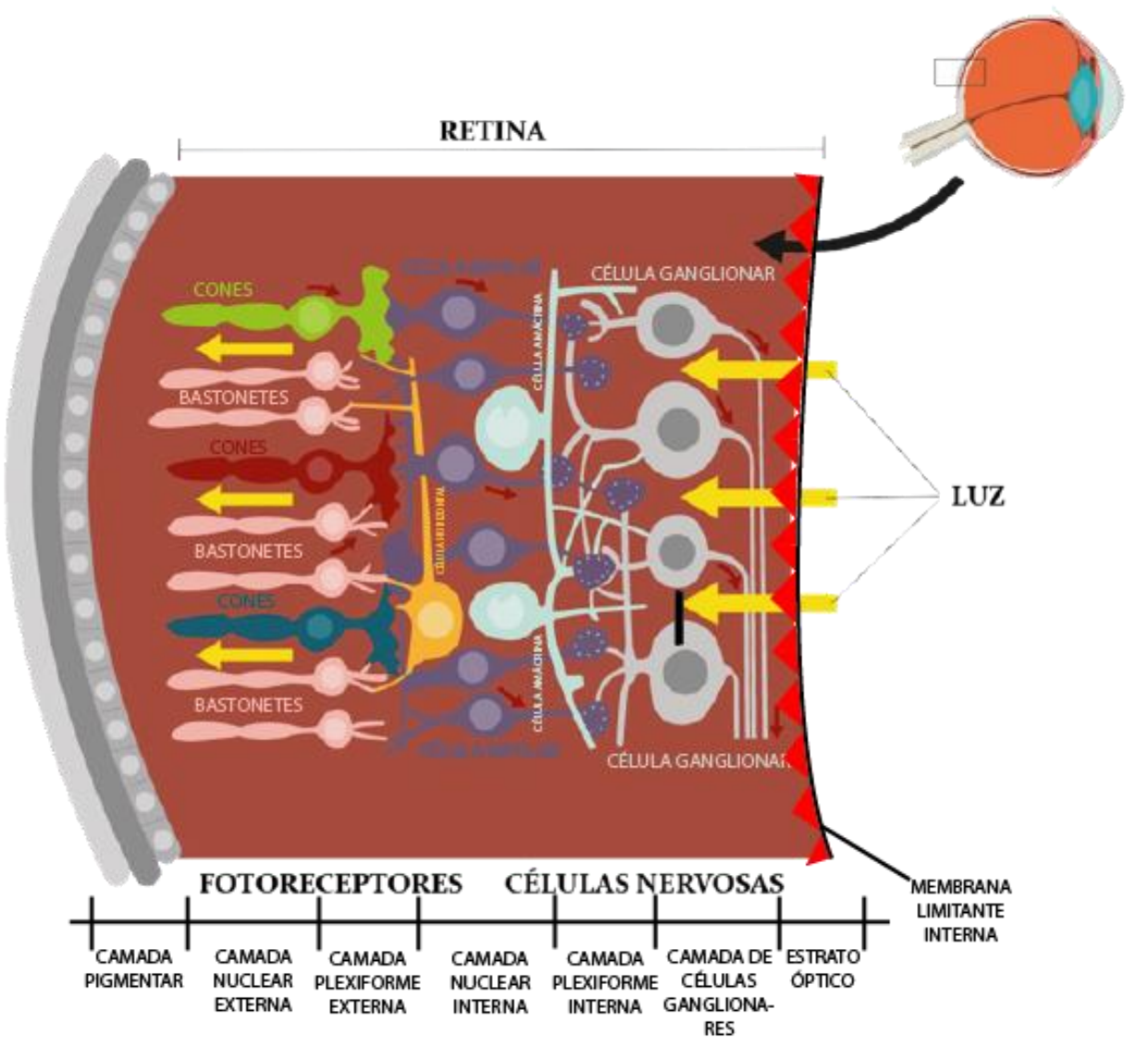

Figura 1 - Fisiologia da Retina do Olho Humano

Fonte: Adaptado pelas autoras de GUYTON e HALL (2011)

A luz captada é orientada pelo cristalino (que funciona como uma lente) e chega à retina, onde é transformada em impulsos nervosos. A retina é a camada do olho humano sensível a luz, onde estão presentes diversas 
estruturas celulares que participam desse processo, chamadas células fotorreceptoras. São duas as células fotorreceptoras anteriormente conhecidas: os cones e os bastonetes. Os cones são células fotorreceptoras relacionadas com a visão diurna e com a percepção das cores (fotópica) e são sensíveis aos comprimentos de onda mais longos do espectro visível. Já os bastonetes, são relacionadas com a visão noturna e a percepção de claro e escuro (escotópica), sendo mais sensíveis aos comprimentos de onda curtos (GUYTON; HALL, 2011).

Em 2002, a partir da descoberta de novos fotorreceptores (ipRGC) dentro do globo ocular humano (BERSON; DUNN; TAKAO, 2002), iniciou-se uma outra fase na área de projeto de iluminação. Essas estruturas conhecidas como "Células Ganglionares da Retina Fotorreceptoras Intrinsecamente Fotossensíveis" (ipRGC), são encontradas por toda a camada da retina do olho humano e extremamente sensíveis a região azul do espectro visível (Figural). Portanto, a luz tem uma influência muito maior do que questões relacionadas somente à visão, regulando o ciclo circadiano, que é o ritmo de vinte e quatro horas de diversos processos fisiológicos humanos, como ritmo de sono e vigília. Até atingir a glândula pineal no centro do cérebro (Figura 2), o raio luminoso é conduzido por um sistema não visual, emitindo mensagem para produção de um hormônio chamado melatonina. Regulado pelo ciclo claro e escuro do dia/noite, esse sistema tem como função a adaptação do corpo humano ao ambiente em que está inserido (BOYCE, 2003). A melatonina é um hormônio que prepara o organismo para o sono, restabelecendo o equilíbrio orgânico e a reduzindo temperatura corporal a noite. A secreção da melatonina é suprimida com maior intensidade pela luz branca e liberada quando há escuro, sendo considerada um marcador de ritmo da estrutura temporal circadiana (BERSON; DUNN; TAKAO, 2002; BOYCE, 2003; TOH, 2008).

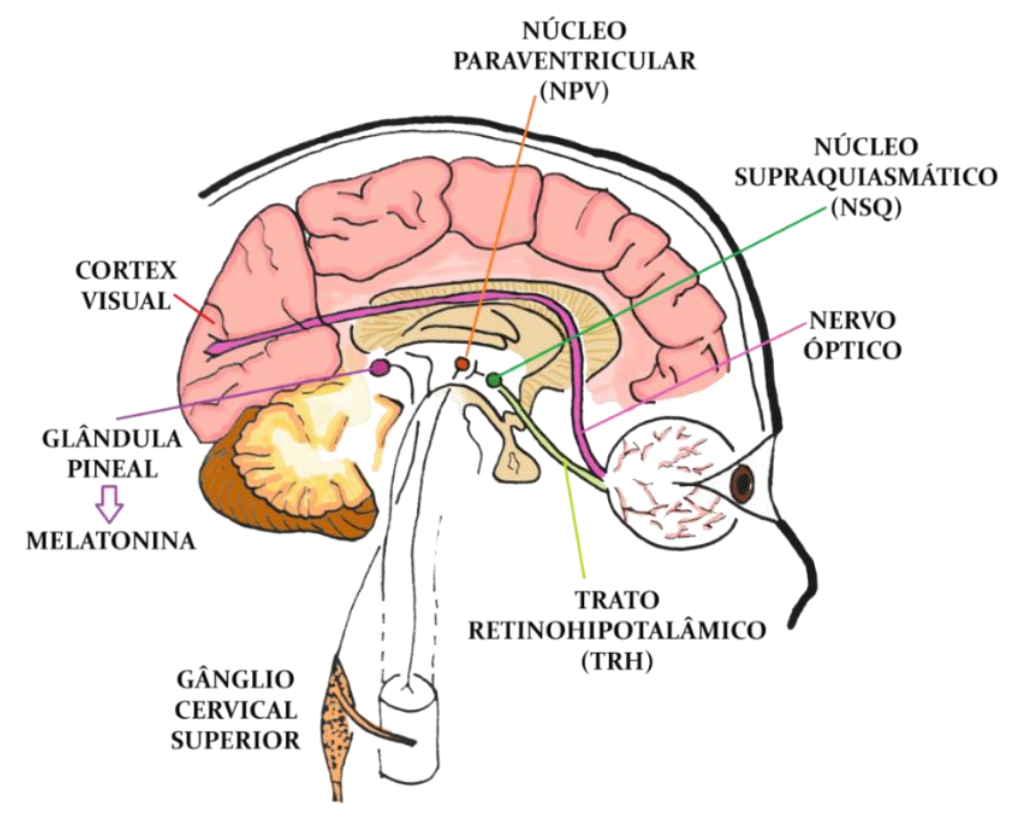

Figura 2 - Sistema que regula o ciclo circadiano no cérebro humano Fonte: Adaptado pelas autoras de BOYCE (2003) 


\section{FUNDAMENTAÇÃO TEÓRICA}

A urbanização crescente das últimas décadas e o aumento do trabalho e iluminação noturnos, fez com que muitos desses processos passassem a sofrer o que a medicina chama de "dessincronização", onde o cérebro é "confundido" mantendo as funções biológicas relacionadas ao ciclo claro mesmo a noite. Ao longo do tempo, ficar nessas "condições artificiais" pode levar ao desenvolvimento de doenças, como provaram pesquisas que buscavam compreender quais os fatores (ou propriedades da luz) influenciavam essa regulação mediada por esse novo fotorreceptor (ZIELINSKA-DABKOWSKA, 2018).

Atualmente a comunidade científica voltou-se para compreensão de como quantificar esses impactos e quais seriam as formas de projetar iluminação tendo o conceito da luz circadiana como base, desafiando tanto arquitetos quanto fabricantes dos equipamentos. Isso se deve pelas diferenças na construção das métricas, onde a Função de Eficiência Fotópica Luminosa $[V(\lambda)]$ é a base de cálculo para quantificar a iluminância em Lux (Ix), focada unicamente no sistema visual. Contudo, as métricas circadianas baseiam-se muito no espectro da luz recebida pelos usuários, possuem funções de sensibilidade espectral específicas focadas no sistema não-visual, se tornando mais um requisito de qualidade na iluminação (REA, 2013).

Duas métricas em desenvolvimento destacam-se atualmente: Lux Melanópico Equivalente (EML) (INTERNATIONAL WELL BUILDING INSTITUTE, 2019; LUCAS et al., 2014) e o Estímulo Circadiano (CS /Luz Circadiana (CLA) (REA; FIGUEIRO, 2018). Nenhuma instituição renomada de iluminação nem nacional nem internacional chegou a um consenso sobre qual delas deve ser utilizada para projetar, portanto ambas são propostas de seus autores sem uma validação pela comunidade científica nem normas técnicas para sua aplicação.

Esse estudo buscou comparar os valores de iluminância para a visão (fotópica) recomendados pela ABNT ISO/CIE NBR 8995-1 (2013) com os valores mínimos das métricas circadianas recomendadas para estimular o sistema não visual.

\subsection{Iluminância - o lux fotópico}

O espectro eletromagnético visível ao olho humano, que se estabelece entre um comprimento de onda entre 380nm a 780nm (GUYTON; HALL, 2011) é o responsável pelo estímulo da visão (Figura 3). A função entre a eficiência luminosa e a escala de comprimento de onda é chamada de Função de Eficiência Fotópica Luminosa $[V(\lambda)]$, no caso da visão diurna, e Função de Eficiência Escotópica Luminosa [ $\left.V^{\prime}(\lambda)\right]$, no caso da visão noturna (BOYCE, 2003; REA, 2013; STEFFY, 2008). 


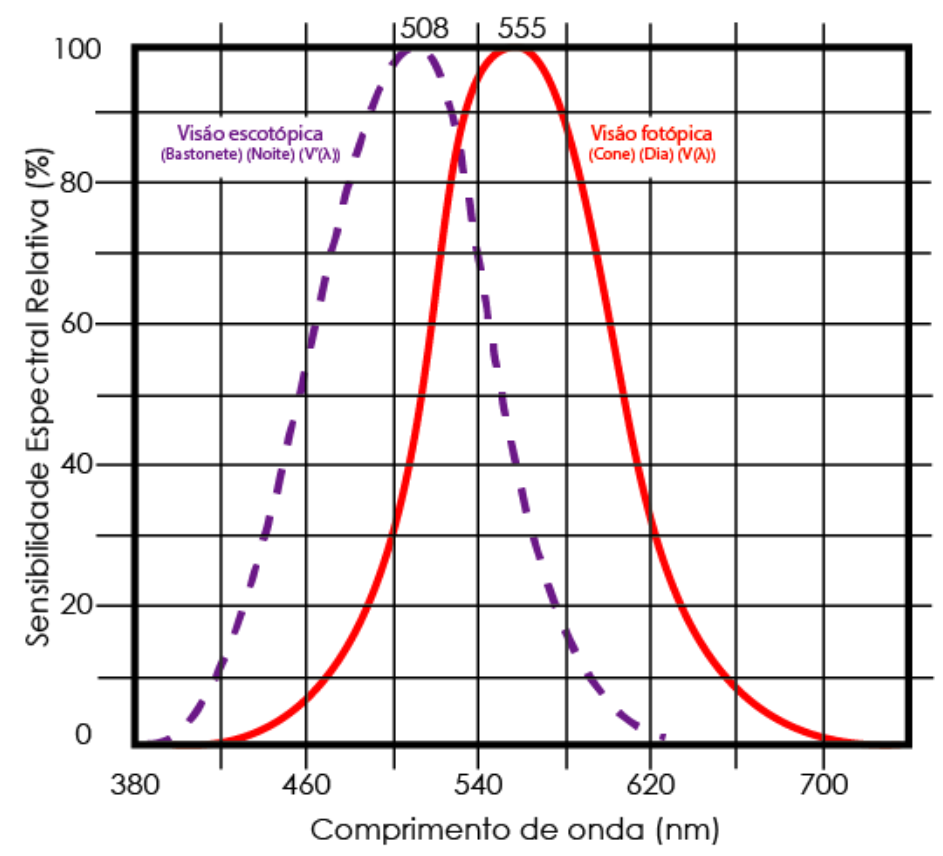

Figura 3 - Sensibilidades Relativas visão fotópica e escotópica Fonte: Adaptado pelas autoras de BOYCE (2003)

A função de eficiência fotópica luminosa $[V(\lambda)]$ foi considerada como base para o desenvolvimento de unidades que receberam o nome de fotométricas. A Comissão Internacional de lluminação (CIE) definiu, em 1924, $V(\lambda)$ como base para quantificar a luz a partir de então, derivando as unidades de medida de luz que se utilizam na indústria da iluminação e em projetos luminotécnicos até hoje, como: fluxo luminoso (lumens); intensidade luminosa (candela); Iuminância, (candela por m2); e iluminância (lux) (BOYCE, 2003; REA, 2013). A Norma Brasileira de lluminação em ambientes de trabalho - ABNT NBR ISO/CIE 8995-1 - indica os valores mínimos de iluminância para execução com conforto das tarefas visuais. Não faz nenhuma menção a iluminação circadiana.

\subsection{O Lux Melanópico Equivalente (EML)}

A aplicação mais célebre do Lux Melanópico Equivalente é a da certificação para edificações WELL Building Certification (INTERNATIONAL WELL BUILDING INSTITUTE, 2019). Nessa certificação, a métrica (z-ópico lux) e a sensibilidade espectral do ipRGC [Função de Resposta Melanopsina - Nz( $\lambda)$ ] desenvolvida por Lucas et al. (2014) foram adaptadas para a aplicação em projetos arquitetônicos, ganhando uma nova abreviação "EML".

A certificação propõe uma constante de cálculo (R), que se multiplica com o Lux Fotópico (L) para obter o valor em EML. Portanto, o cálculo se desenvolve a partir da Equação (1).

$$
E M L=L \times R
$$

onde, EML = Lux Melanópico Equivalente (EML);

L = LuX Fotópico (lux);

$\mathrm{R} \quad=$ constante de cálculo.

No cálculo, o arquivo "Melanopic Ratio" é disponibilizado, como uma ferramenta de planilha de Excel, para o cálculo do EML. O projetista insere a lâmpada ou fonte de luz com suas características de espectro, denominada 
Distribuição Espectral de Potência Radiante (DEP) ou Spectral Power Distribution (SPD), em inglês, a planilha de cálculo determina a constante que deve ser multiplicada pelo valor de iluminância em lux (Lux Fotópico) determinado no ambiente, resultando no valor em EML.

A recomendação para a iluminação circadiana indica que valores mínimos de EML devem ser atingidos entre as $9 \mathrm{~h}$ e $13 \mathrm{~h}$, sendo reduzidos após as $20 \mathrm{~h}$. Também, recomenda que a iluminância (lux), deve ser mensurada no plano vertical ao nível do olho do ocupante, simulando a entrada de luz. Em escritórios, as estações de trabalho o nível mínimo deve ser alcançado a 0,45 $\mathrm{m}$ acima da superfície de trabalho e em espaços sem estações a 1,40 m acima da superfície do piso.

Conforme sintetizado nas Figuras 4 e 5, também há valores mínimos para espaços com e sem iluminação natural (INTERNATIONAL WELL BUILDING INSTITUTE, 2019).

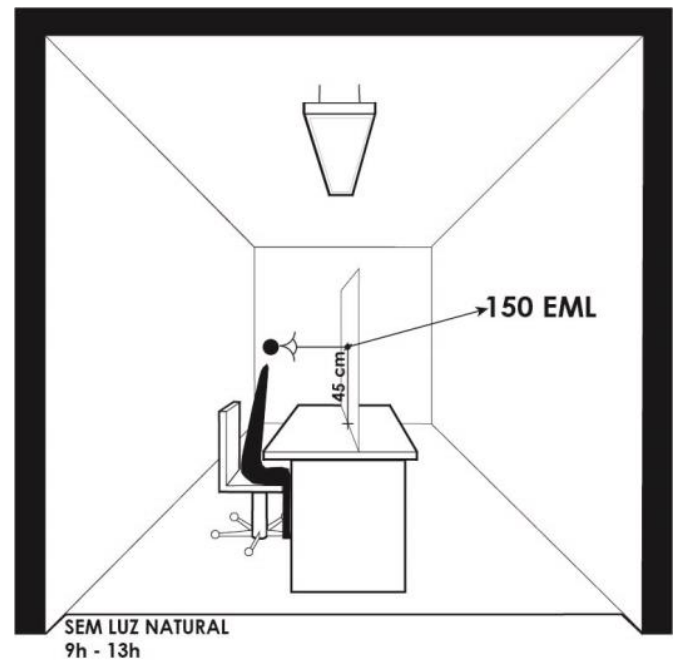

1 PONTO

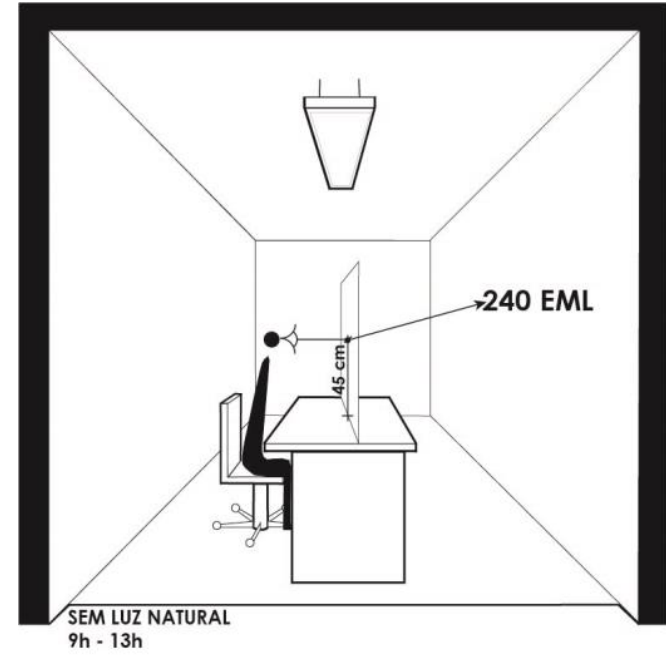

3 PONTOS

Figura 4 - Valores mínimos EML (WELL V2) sem luz natural Fonte: Autoras (2019)

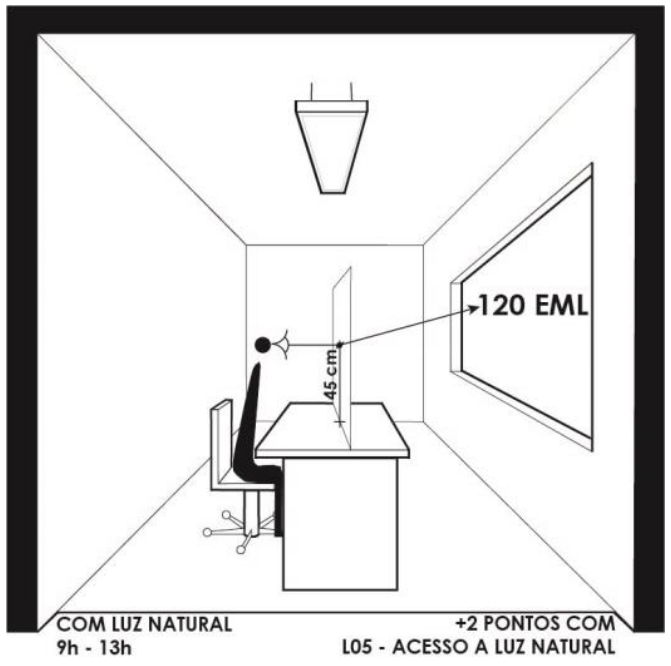

1 PONTO

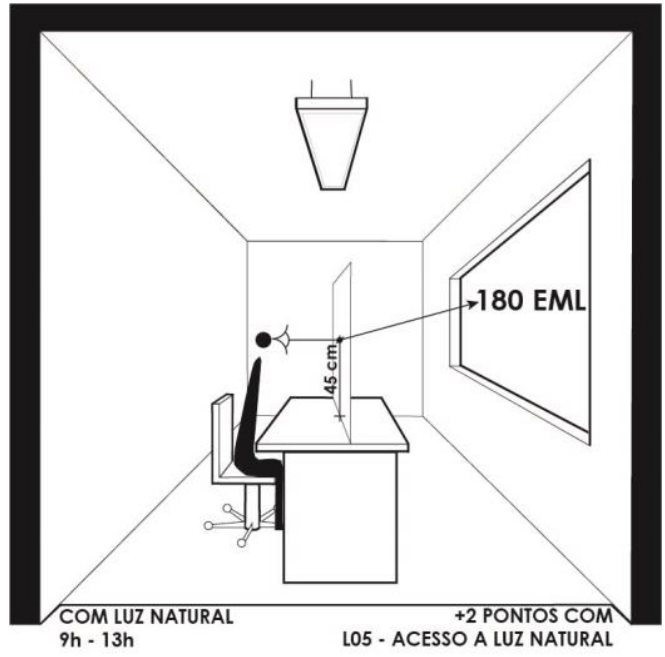

3 PONTOS

Figura 5 - Valores mínimos EML (WELL V2) com luz natural Fonte: Autoras (2019) 


\subsection{A Luz Circadiana $\left(\mathrm{CL}_{\mathrm{A}}\right)$ e o Estímulo Circadiano (CS)}

Essa métrica e suas unidades são baseadas no estímulo circadiano, com conceitos completamente diferentes da iluminância e com algumas variações em relação ao EML. Rea e Figueiro (2018) apresentam o conceito de Luz Circadiana (CLA) e o Estimulo Circadiano (CS). As duas novas unidades, respectivamente, indicam a sensibilidade espectral (CLA) e absoluta (CS) do sistema circadiano humano. De acordo com os modelos desenvolvidos, a irradiância espectral na córnea é primeiro convertida em $C L_{A}$, refletindo a sensibilidade espectral do sistema circadiano e então, em seguida, transformado em CS, refletindo a sensibilidade absoluta do sistema, isso é, incluindo a interferência de outros fotorreceptores como os cones e os bastonetes no estimulo final circadiano (REA; FIGUEIRO, 2018).

CS é a eficácia calculada da irradiância espectralmente ponderada na córnea desde o limiar (CS $=0,1)$ até à saturação (CS $=0,7)$, assumindo uma duração fixa de exposição de 1 hora. Já o $\mathrm{CL}_{\mathrm{A}}$ é a irradiância na córnea que reflete a sensibilidade espectral do sistema circadiano humano, medida pela supressão aguda da melatonina após uma exposição de 1 hora.

Para facilitar o cálculo das unidades circadianas, os autores apresentam uma ferramenta para o planejamento e o desenvolvimento do projeto circadiano: a CS Calculator (FIGUEIRO; REA; WARD, 2019).

A Figura 6 mostra os valores mínimos necessários em uma estação de trabalho fixa em um ambiente iluminado pela luz elétrica e natural. O nível mínimo recomendado de Estimulo Circadiano é de $C S \geq 0,3$ durante o período das $6 \mathrm{~h}$ às $14 \mathrm{~h}$, enquanto entre $14 \mathrm{~h}$ e $5 \mathrm{~h} 59 \mathrm{~min}$ o CS $<0,3$. O CS não orienta uma altura fixa para se mensurar a iluminância (lux), mesmo recomendando que isso seja realizado no plano vertical ao nível do olho do ocupante. Utilizam o Daysimeter (uma espécie de luxímetro) colocado na altura do olho do usuário, variando sua altura de acordo com cada indivíduo.
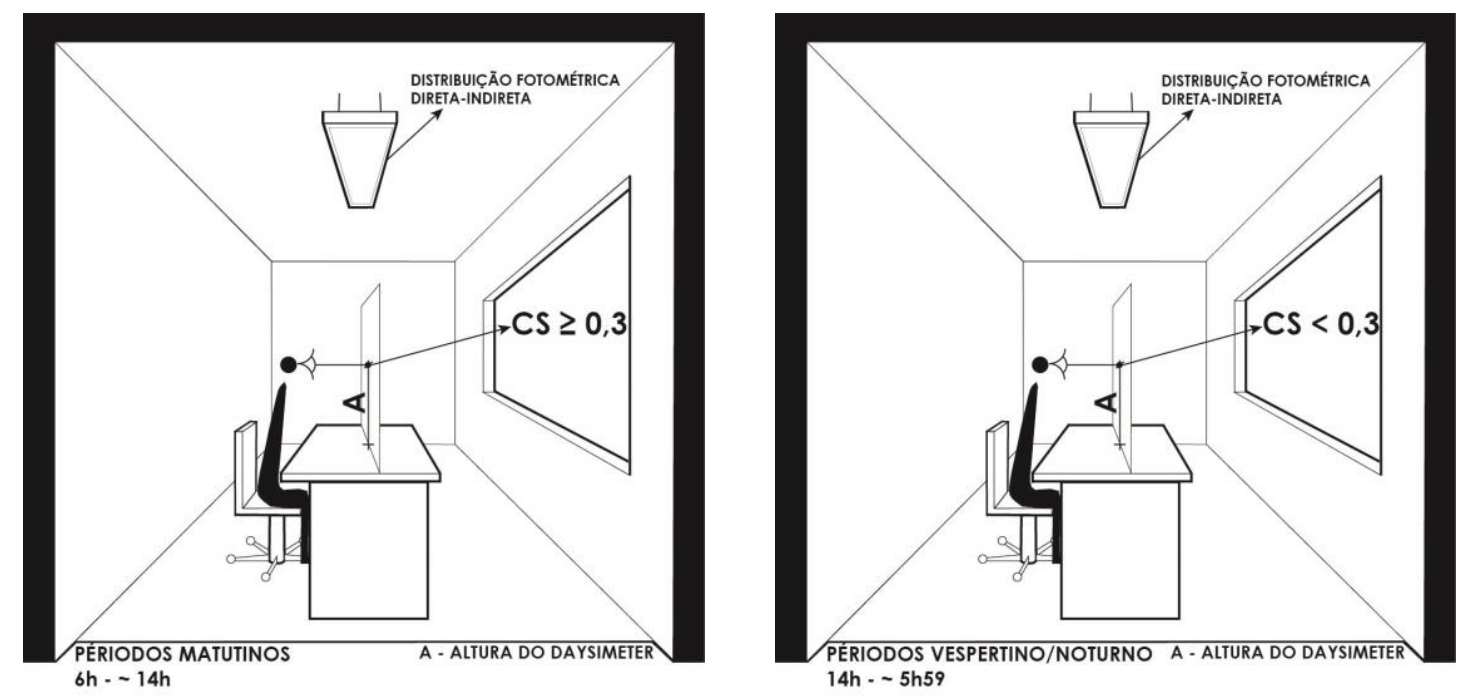

Figura 6 - Valores mínimos CS

Fonte: Autoras (2019)

\subsection{Funções de sensibilidade espectral circadianas}

Um aspecto em que as duas métricas circadianas diferem em sua metodologia de cálculo diz respeito a curva de sensibilidade espectral 
circadiana adotada por cada uma (Figura 7). Enquanto 0 EML considera 0 pico máximo ( $\lambda$ max) da sua sensibilidade na distribuição espectral de potência radiante $[\mathrm{Nz}(\lambda)]$ aos $480 \mathrm{~nm}$, a $\mathrm{CL}_{\mathrm{A}}$ (consequentemente o CS) considera o $\lambda$ max da sua sensibilidade aos 460nm não sendo possível estabelecer uma relação direta entre valores de EML e CS/CLA. Além disso, podemos dizer que o CS/CLA cria uma nova unidade, enquanto o EML tenta equivaler a sua unidade a unidade fotópica, o lux ou seja, ao conceito de iluminância para visão.



Figura 7 - Funções de sensibilidade espectral circadianas-

Fonte: Adaptado pelas autoras de CLARK; LESNIAK (2017)

\section{RESULTADOS E DISCUSSÃO}

\subsection{Estudo de caso 1: projetos luminotécnicos para iluminação fotópica segundo a iluminância da ABNT NBR 8995-1}

Com as fontes fluorescentes (4000K), para atingir o mínimo de 500 lux ao nível da mesa de altura $0,75 \mathrm{~m}$, foram necessárias três luminárias fluorescentes, com potência total de $336 \mathrm{~W}\left(10,41 \mathrm{~W} / \mathrm{m}^{2}\right)$, localizadas acima e centralizadas com a superfície de trabalho. A iluminância horizontal média na superfície de trabalho foi de 565 lux, enquanto a iluminância vertical média ao nível do observador (1,20m do piso e 0,45 m acima da superfície de trabalho) foi de 190 lux (Fig.4).

Com as fontes LED (4000K), para atingir o mínimo de 500 lux ao nível da mesa de altura $0,75 \mathrm{~m}$, foram necessárias quatro luminárias LED, com potência total de $92 \mathrm{~W}\left(2,85 \mathrm{~W} / \mathrm{m}^{2}\right)$, localizadas acima e centralizadas com a superfície de trabalho. A iluminância horizontal média na superfície de trabalho foi de 528 lux, enquanto a iluminância vertical média ao nível do observador (1,20 m do chão, 0,45 m acima da superfície de trabalho) foi de 186 lux (Figura 8). 

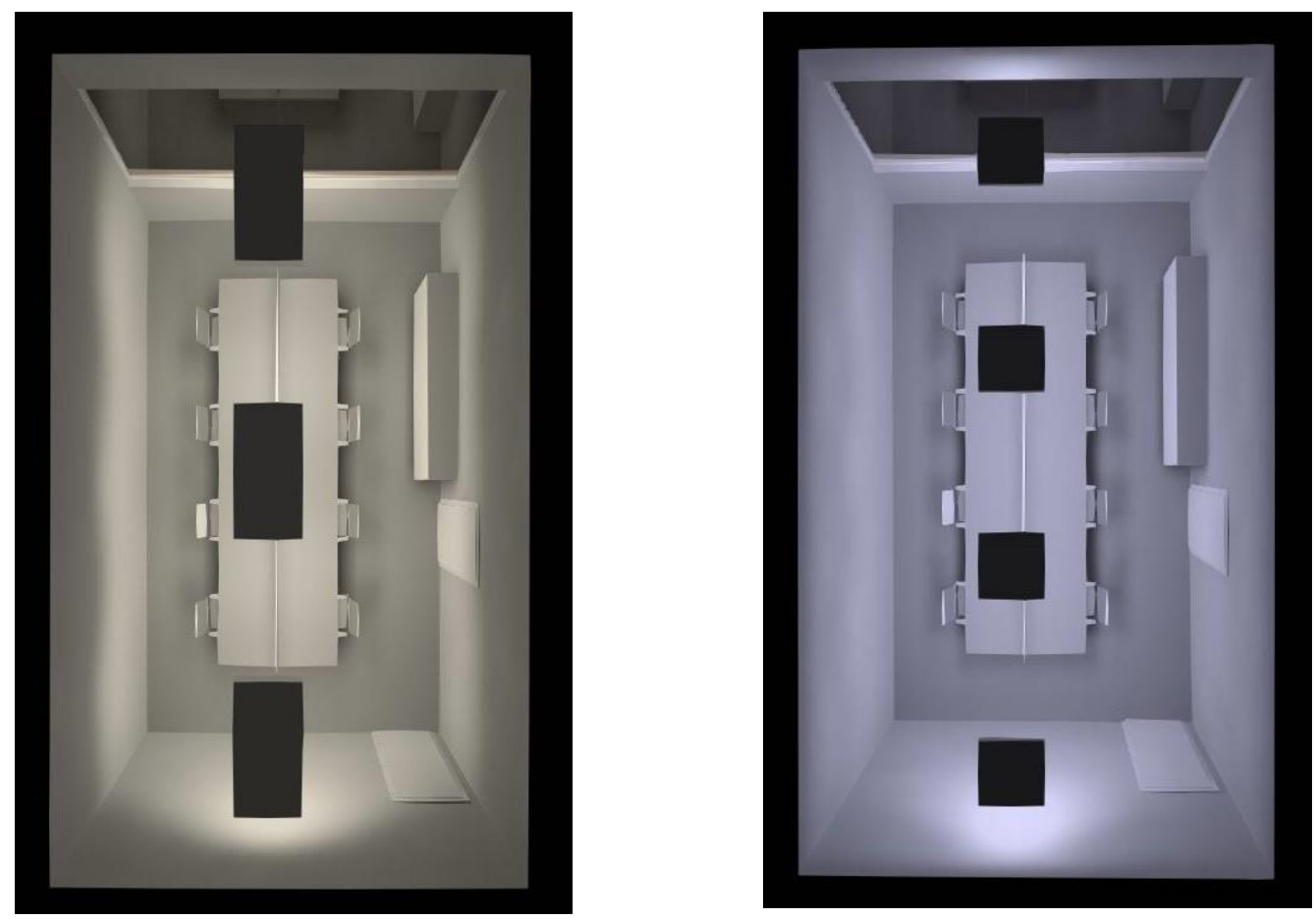

Figura 8 - Simulação DIALux iluminância fotópica: fluorescente (esquerda) e LED (direita)

Fonte: Autoras (2019)

\subsection{Estudo de caso 2: projetos luminotécnicos para iluminação circadiana com EML a partir da iluminância fotópica}

Com valores de DEP da fluorescente (4000K) utilizados na ferramenta "Melanopic Ratio", obtém-se uma constante de cálculo (R) de 0,588, que multiplicada pela iluminância vertical média de 190 lux temos o valor de 111,72 EML. Com valores de DEP do LED (4000K) utilizados na ferramenta "Melanopic Ratio", ela nos fornece uma constante de cálculo (R) de 0,76 que multiplicada pela iluminância vertical média de 186 lux, temos o valor de 141, 36 EML.

\subsection{Estudo de caso 3: projetos luminotécnicos para iluminação circadiana com CS/CLA a partir da iluminância fotópica}

Com valores de DEP fluorescente (4000K) utilizados na ferramenta na "Web CS Calculator", mantendo o valor de 0,5 em "Macular Pigment Optical Density", e o valor iluminância vertical média de190 lux obtém-se um CS =0,245 e CLA = 203. Com valores de DEP LED (4000K) utilizados na ferramenta "Web CS Calculator", mantendo o valor de 0,5 em "Macular Pigment Optical Density", e o valor iluminância vertical média de 186 lux obtém-se um CS =0,202 e CLA = 157.

\subsection{Análise comparativa entre os casos}

Os projetos com a iluminância mínima recomendada pela ABNT NBR 8995-1 (2013), com ambas fontes luminosas, não atingiram o valor necessário para início da supressão da melatonina (desejável durante a manhã e o início da tarde) em nenhuma das métricas circadianas. Enquanto o mínimo recomendado pela EML é um valor de 150 EML para um ponto em ambientes sem iluminação natural, foram obtidos 111,72 EML (fluorescente) e 141,36 EML 
(LED). Já o CS mínimo recomendado é de CS $\geq 0,3$, mas as simulações obtiveram CS $=0,245$ (fluorescente) e $C S=0,202$ (LED). Na fluorescente com $111,72 \mathrm{EML}$ e CS $=0,245$, precisaríamos de 10,41 W/m². Já na LED com 141,36 $E M L$ e CS $=0,202$, precisaríamos de $2,85 \mathrm{~W} / \mathrm{m}^{2}$.

Os valores obtidos nos casos 2 e 3 indicam que, se desejamos uma iluminação circadiana, devemos aumentar a iluminância para visão, com consequente aumento do consumo energético, considerando que a eficiência luminosa (lumens por watt) dos LED sempre será maior. Indica que se deve pensar a iluminação não somente com a iluminância horizontal e que a iluminância vertical, com a luz que chega aos olhos é a mais importante para o sistema circadiano.

A principal similaridade entre os métodos de conversão de iluminância fotópica para as unidades circadianas está na necessidade dos dados gráficos completos de DEP da fonte luminosa. Ambas as métricas oferecem ferramentas de cálculo com lâmpadas padrão, permitindo a inserção de lâmpadas especificas pelo projetista, sendo conhecidos os dados gráficos completos de DEP da fonte de luz. Há maior disponibilidade de dados de DEP de fontes de luz padrão na ferramenta método CS/ CLA, além da possibilidade de adicionar mais de uma fonte de luz em um mesmo cálculo. Nem sempre os fabricantes fornecem essas especificações, o que torna difícil e demorado para os projetistas a obtenção dos mesmos.

Os DEP causam impacto direto na formulação das unidades circadianas, pois para a sua derivação a temperatura de cor (TCC) não é o principal agente. Verifica-se a diferença nos casos 2 e 3 de duas fontes de luz com DEP diferentes, porém com a mesma TCC de 4000K. Enquanto em EML, a fluorescente (1 1 1,72 EML) tem um valor menor que a fonte de LED (141,36 EML), no valor de CS a fonte fluorescente (CS $=0,245$ ) tem um valor maior que da fonte LED (CS = 0,202). Por isso, quando falamos de iluminação circadiana a alteração da TCC não é o requisito que deve ser variado, mas sim o espectro (DEP) da fonte luminosa.

Quanto ao software, detectamos uma dificuldade para relacionar os valores de DEP das ferramentas de cálculo circadiano na simulação em DIALux, já que o programa não permite adicionar DEP externos. Isso significa que para que exista maior rigor na conversão da iluminância fotópica para a circadiana, por qualquer uma das métricas, é necessário um software de simulação de iluminância fotópica que permita a manipulação do espectro da lâmpada, para que a correspondência entre as especificações utilizadas esteja precisa. Portanto, não consideramos o DIALux, atualmente a ferramenta mais usual nos escritórios, adequada ao processo de projeto de iluminação circadiana.

Observa-se que a EML não considera a idade do usuário no cálculo, sendo o padrão para pessoas de todas as idades, diferentemente da CS/CLA que estabelece faixas etárias a serem selecionadas na ferramenta de cálculo. Isso torna o cálculo mais preciso, tendo em vista que o envelhecimento do olho também interfere na resposta circadiana individual.

A utilização do Daysimeter no cálculo do $C S / C L_{A}$ faz com que exista maior precisão na avaliação da iluminância vertical, porque a aferição ocorre o mais perto da córnea, possibilitando a variação do plano de medição vertical de acordo com o usuário. Porém, na prática, há de se estabelecer um padrão 
de altura para cálculo, uma vez que em um escritório existem pessoas reais de diferentes alturas. Além disso, a aquisição de equipamentos específicos e ainda não comercializados por parte dos escritórios também inviabiliza a aferição do impacto circadiano, pelo menos por enquanto.

\section{CONSIDERAÇÕES FINAIS}

O processo de projeto luminotécnico precisa ser revisto na prática arquitetônica. As descobertas dos impactos da iluminação na saúde do homem aumentaram a responsabilidade dos profissionais. Porém, ainda não há conhecimento consolidado de como projetar a iluminação que atenda as questões fisiológicas relacionadas aos ritmos circadianos. Não há normas técnicas nem consenso na comunidade científica sobre qual a métrica que melhor pode aferir o impacto da luz nos usuários. Por isso, a importância de testar 0 que as pesquisas têm produzido, explorando as ferramentas atualmente oferecidas para poder transferir esse conhecimento, mesmo que incompleto, para os projetistas de iluminação. Muitos projetos são executados sem nenhuma fundamentação teórica, com o argumento que é melhor fazer alguma coisa do que nada. Porém, em se tratando de variáveis ambientais que interferem na saúde humana, todo cuidado é necessário. Esse estudo mostrou que a ferramenta mais utilizada para projeto luminotécnico talvez não sejam a mais adequada a partir dos conceitos de luz circadiana. Novos equipamentos para aferição da luz deverão ser comercializados e as disciplinas dos cursos de arquitetura deverão atualizar os seus conteúdos dos currículos de graduação. Além disso, fica claro que projetar uma iluminação circadiana sempre envolverá maiores custos relacionados com o consumo energético, seja qual for a fonte escolhida. Conhecer o espectro das lâmpadas e suas características de distribuição será fundamental para os novos projetistas. Portanto, concluímos que discutir formas de traduzir o conhecimento da pesquisa para pratica profissional deve ser o foco das pesquisas, para que se possa projetar considerando a luz circadiana, entendida como fator essencial da qualidade de um ambiente.

\section{AGRADECIMENTO}

Ao CNPq pelo auxílio financeiro ao projeto mãe "A cidade que nunca dorme".

\section{REFERÊNCIAS}

ASSOCIAÇÃO BRASILEIRA DE NORMAS TÉCNICAS (ABNT). ABNT NBR ISO/CIE 8995-1: Iluminação de ambientes de trabalho, Parte 1: Interior. São Paulo, p. 54, 2013.

BERSON, D. M.; DUNN, F. A.; TAKAO, M. Phototransduction by Retinal Ganglion Cells That Set the Circadian Clock. Science, Washington, v. 295, n. 5557, p. 1070-1073, 2002.

BOYCE, P. R. Human Factors in Lighting. 1. ed. New York: Taylor\&Francis, 2003.

CLARK, E.; LESNIAK, N. Circadian Lighting Solutions Are Real and Important Why Aren't They Being Used? Metropolis, New York, dez. 2017.

FIGUEIRO, M. G.; REA, M. S.; WARD, G. J. Web CS Calculator. 2019. 
GUYTON, A. C.; HALL, J. E. Tratado de Fisiologia Médica. 11. ed. São Paulo: Elsevier Inc., 2011.

INTERNATIONAL WELL BUILDING INSTITUTE. Circadian Lighting Design v2. 2019. LUCAS, R. J. et al. Measuring and using light in the melanopsin age. Trends in Neurosciences, [s. I.], v. 37, n. 1, p. 1-9, 2014.

REA, M. S. Value Metrics for better lighting. 1. ed. Bellingham: SPIE Press, 2013.

REA, M. S.; FIGUEIRO, M. G. Light as a circadian stimulus for architectural lighting. Lighting Research \& Technology, [s. I.], v. 50, n. 4, p. 497-510, 2018.

STEFFY, G. R. Architectural Lighting Design. 1. ed. Hoboken: John Wiley \& Sons, 2008.

TOH, K. L. Basic Science Review on Circadian Rhythm Biology and Circadian Sleep Disorders. Academy of Medicine Singapore, [s. I.], v. 37, n. 8, p. 662-668, 2008.

TOUITOU, Y.; REINBERG, A.; TOUITOU, D. Association between light at night, melatonin secretion, sleep deprivation, and the internal clock: Health impacts and mechanisms of circadian disruption. Life Sciences, [s. I.], v. 173, p. 94-106, 2017.

ZIELINSKA-DABKOWSKA, K. M. Make lighting healthier. Nature, New York, v. 553, n. 7688, p. 274-276, 2018. 